Sādhanā Vol. 39, Part 2, April 2014, pp. 487-509. (C) Indian Academy of Sciences

\title{
Temporal moment analysis of solute transport in a coupled fracture-skin-matrix system
}

\author{
V RENU and G SURESH KUMAR* \\ Department of Ocean Engineering, Indian Institute of Technology Madras, \\ Chennai 600 036, India \\ e-mail: renuvalsala@gmail.com; gskumar@iitm.ac.in
}

MS received 28 October 2013; revised 24 December 2013; accepted 25

December 2013

\begin{abstract}
In the present study, method of temporal moments has been used to analyse the transport characteristics of reactive solute along fracture in a coupled fracture-skin-matrix system. In order to obtain the concentration distribution within the fracture, a system of coupled partial differential equations for fracture, fractureskin and rock-matrix has been solved numerically in a pseudo two-dimensional domain using implicit finite difference method. Subsequently, lower order temporal moments of solute have been computed from the concentration distribution to analyse the transport characteristics of solutes in the fracture. This study has been done by considering an inlet boundary condition of constant continuous source in a single fracture. The effect of various fracture-skin parameters like porosity, thickness and diffusion coefficient on the transport of solutes have been studied by doing sensitivity analyses. The effect of nonlinear sorption and radioactive decay of solutes have also been analysed by carrying out simulations for different sorption intensities and decay constants. Numerical results suggested that the presence of fracture-skin significantly influences the transport characteristics of reactive solutes along the fracture.
\end{abstract}

Keywords. Single fracture; fracture-skin; numerical model; temporal moment; sorption; decay.

\section{Introduction}

Study on fluid flow and transport of solute through fractures has been an area of great interest among hydro-geologists during past few decades. Flow though fracture has major influence on fluid migration within a fractured reservoir since the high permeability fracture forms the preferential pathway within the low permeability rock-matrix. The major transport processes which affect the solute transport through fracture are advection, dispersion, matrix diffusion, sorption and degradation. Among the above processes matrix diffusion plays an important role in deciding the solute mobility, dispersion and concentration distribution along the fracture.

${ }^{*}$ For correspondence 
Several studies have suggested the possibility of presence of a thin permeable layer known as fracture-skin at fracture-rock matrix interface (Moench 1984, 1995; Sharp 1993; Fu et al 1994; Driese et al 2001). According to Sharp (1993) fracture skins are the coatings or zones of alteration along fracture surfaces caused by mineral-water interactions, organic activity, and adherence of colloidal materials (including clay minerals) to the fracture surfaces. Sharp et al (1996) have observed fracture skins on near-surface fractures in a wide variety of environments which include igneous rocks (tuffs, basalts and granites), sedimentary rocks (limestones, shales and sandstones) and unconsolidated alluvial sediments. Since the primary porosity of the above host rocks vary widely, the corresponding porosity of the fracture-skin may also be expected to be significant. A few more studies have been conducted to study the effect of fracture-skin in the solute transport and among them, few studies have concluded that the presence of fractureskin in the form of mineral precipitation (Fu et al 1994) organic growth material (Robinson \& Sharp 1997) and clay filling (Driese et al 2001) have reduced the permeability, where as some other studies have concluded that the presence of fracture-skin has resulted in an increase of permeability by developing micro-fractures (Polak et al 2003; Garner \& Sharp 2004). Since the solute transport parameters of fracture-skin like permeability, porosity, diffusion coefficient and retardation factor may significantly differ from that of the associated rock-matrix, the presence of fracture skin may either mitigate or enhance the mass transfer at the interface, and in turn, influence the fluid flow and solute transport within the fracture (Fu et al 1994; Kreisel \& Sharp 1996; Landrum 2000; Phyu 2002; Robinson et al 1998; Sharp 1993; Sharp et al 1995; Zimmerman et al 2002; Renu \& Suresh Kumar 2012). Modelling of contaminant transport has been carried out in a set of parallel fractures with fracture skin by Robinson et al (1998). Garner \& Sharp (2004) studied the solute transport in granitic rocks with fracture skin using field data from two different sites. Suresh Kumar \& Sekhar (2005) investigated the sensitivity of fracture velocity, fracture dispersivity, fracture spacing, matrix diffusion coefficient and matrix porosity on mobility and spreading of solutes using method of spatial moments in a coupled fracturematrix system. Suresh Kumar \& Ghassemi (2006) have further extended the spatial-moment analysis for studying non-isothermal solute transport with simplified dissolution/precipitation of quartz in a single fracture. Later, Sekhar et al (2006) and Suresh Kumar (2008) have investigated the effect of linear and non-linear sorption on dispersivity and macro-dispersion coefficient in a coupled fracture-matrix system. Suresh Kumar (2009) has developed a numerical model to analyse the effect of sorption intensities on solute mobility in a fracture-matrix formation. Natarajan $\&$ Suresh Kumar (2010) developed a numerical model to analyse the colloid facilitated radionuclide transport in a coupled fracture-skin-matrix system. Sharma et al (2012) has numerically analysed using temporal moments the reactive transport chemicals in fractured impermeable and permeable formation. Recently, Renu \& Suresh Kumar (2012) have numerically analysed mobility and spreading of solutes using spatial moment analysis in a coupled fracture-skin-matrix system and they have concluded that the presence of fracture-skin significantly influences the mobility and spreading of solutes along the fracture in comparison with a coupled fracture-matrix system in the absence of fracture-skin.

In this study, we investigate the reactive transport modelling in a coupled fracture-skin-matrix system using numerical modelling along with first and second order temporal moment analysis. It can be noted that the temporal moments do not need averaging over large area or volume unlike spatial moment, while the estimated temporal moments at different distances from the source can be used to investigate the variations of the controlling parameters with scale (Woodbury \& Rubin 2000). In addition, using the method of temporal moments, arrival time data can be obtained and this data can be used to forecast environmental impact of migrating contaminant. 
Further, the temporal moment analysis helps the investigator to have an idea about the time at which a particular contaminant arrive at a locality and the standard deviation with which mean arrival time can be predicted (Naff 1992). Temporal moment analysis is easier to perform, since it is easier to collect arrival time data at a few observation points in field or laboratory column investigations (Bardsley 2003). Valocchi (1990) made use of method of temporal moments to analyse problems involving sorbing solute transport in soils and aquifers and has stated that temporal moments are very useful in one-dimensional systems like laboratory-scale soil columns. In this context, the goal of the present study is to apply temporal moment analysis in order to quantify the velocity and dispersion coefficients of the solutes along the fracture in a coupled fracture-skin-matrix system.

\section{Physical system and governing transport equations}

The conceptual model corresponding to a coupled fracture-skin-matrix system (Robinson et al 1998; Renu \& SureshKumar 2012) is adopted in figure 1. The principal transport mechanisms considered along the fracture are advection, hydrodynamic dispersion, nonlinear sorption, first-order radioactive decay and solute transfer to adjacent fracture-skin through diffusion. The transport of solutes along the fracture is considered to be one-dimensional since the migration of solute along the high permeability fracture is faster than in the rock-matrix (Suresh Kumar \& Sekhar 2005; Sekhar et al 2006; Sekhar \& Suresh Kumar 2006; Suresh Kumar 2009) and the ground water velocity is assumed to be constant in the fracture. It is also assumed that complete mixing of solutes is happening normal to the direction of flow due to the free molecular diffusion, and in turn, result in uniform solute concentration.

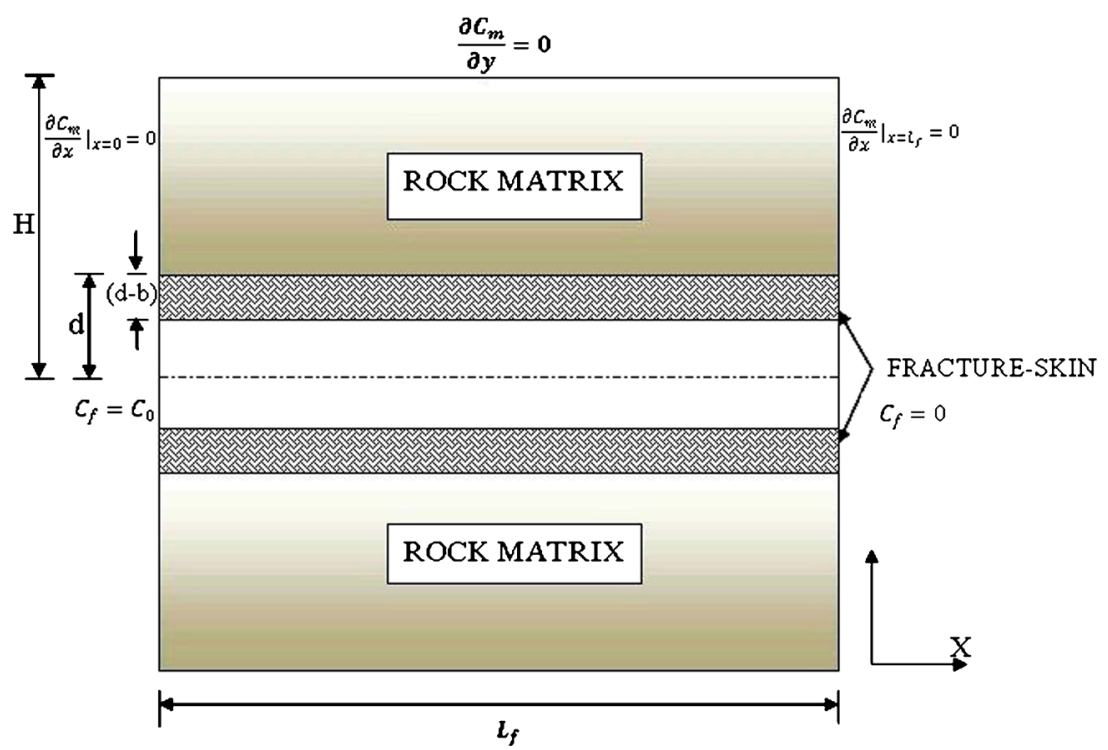

Figure 1. Schematic representation of solute transport in a uniform aperture single fracture with a constant source input $C_{0}$ and no flux conditions at the matrix. 
If Fickian regime dispersion is assumed along the fracture and if transverse dispersion is neglected as compared to longitudinal dispersion, the volume concentration of solute in the fracture obeys the following transport equation (Robinson et al 1998).

$$
\begin{gathered}
R_{f} \frac{\partial C_{f}}{\partial t}=D_{L} \frac{\partial^{2} C_{f}}{\partial x^{2}}-V_{0} \frac{\partial C_{f}}{\partial x}-\lambda C_{f}+\frac{\theta_{s} D_{s}}{b} \frac{\partial C_{s}}{\partial y} \mid y=b, \\
\text { where } D_{L}=\alpha_{0} V_{0}+D^{*} .
\end{gathered}
$$

The transport processes in immobile zones of fracture-skin and rock-matrix are expressed as

$$
\begin{gathered}
R_{s} \frac{\partial C_{s}}{\partial t}=D_{s} \frac{\partial^{2} C_{s}}{\partial y^{2}}-\lambda C_{s}, \\
R_{m} \frac{\partial C_{m}}{\partial t}=D_{m} \frac{\partial^{2} C_{m}}{\partial y^{2}}-\lambda C_{m},
\end{gathered}
$$

where $b$ represents the thickness of half fracture aperture $(\mathrm{L}) ;(d-b)$ represents the skin thickness $(\mathrm{L})$; $H$ represents the thickness of half fracture spacing (L); $C_{f}, C_{s}$ and $C_{m}$ represent the volume concentrations of solute in fracture, fracture-skin and rock-matrix, respectively $\left(M L^{-3}\right), \mathrm{x}$ represents the space coordinate along the flow direction in the fracture plane (L), y represents the space coordinate perpendicular to the fracture plane $(\mathrm{L}), \mathrm{t}$ represents the time coordinate $(\mathrm{T})$, $D_{L}$ represents hydrodynamic dispersion coefficient in the fracture $\left(\mathrm{L}^{2} \mathrm{~T}^{-1}\right), \alpha_{0}$ represents the longitudinal dispersivity in the fracture $(\mathrm{L}), D^{*}$ represents the molecular diffusion coefficient of solute in free water $\left(\mathrm{L}^{2} \mathrm{~T}^{-1}\right), V_{o}$ represents the mean water velocity in fracture $\left(\mathrm{LT}^{-1}\right), D_{s}$ and $D_{m}$ represent the effective diffusion coefficients in fracture-skin and rock-matrix, respectively, $\theta_{s}$ represents the porosity of fracture-skin, $\lambda$ represents the coefficient of radio-active decay $\left(\mathrm{T}^{-1}\right)$, and $R_{f}, R_{s}$ and $R_{m}$ represent the retardation factors in fracture, fracture-skin and rock-matrix, respectively (-).

The expressions for the retardation factors describing the instantaneous linear equilibrium sorption isotherm in fracture, fracture-skin and rock-matrix have been provided in Eqs. 5(a)-(c).

$$
\begin{aligned}
& R_{f}=1+\frac{K_{f}}{b}, \\
& R_{s}=1+\frac{\rho_{s} K_{s}}{\theta_{s}}, \\
& R_{m}=1+\frac{\rho_{m} K_{m}}{\theta_{m}} .
\end{aligned}
$$

Here $K_{f}$ represents the area based surface distribution coefficient, described as the fracture surface area available for sorption per unit aqueous volume of the fluid within the fracture with length units. The notations $K_{m}$ and $K_{s}$ represent the volume based distribution coefficients within the rock-matrix and fracture-skin, respectively with units $\left[\mathrm{L}^{3} / \mathrm{M}\right]$, describing the volume of sorption sites available within the rock-matrix, and fracture-skin per unit mass of solutes. $\theta_{s}$ and $\theta_{m}$ represent the porosity of fracture-skin and rock-matrix, respectively; $\rho_{s}$ and $\rho_{m}$ represent the mass density of fracture-skin and rock-matrix respectively $\left(M L^{-3}\right)$. However, equilibrium sorption is often better represented by nonlinear sorption isotherms and most commonly used 
sorption relationship is Freundlich sorption isotherm (Weber et al 1991; Renu \& Suresh Kumar 2012) and can be expressed as

$$
S=K_{d} C^{n}
$$

where $C$ represents the volume concentration of solute $\left(\mathrm{ML}^{-3}\right), S$ represents the sorbed concentration $\left(\mathrm{MM}^{-1}\right), K_{d}$ represents the partition or distribution coefficient $\left(\mathrm{L}^{3} \mathrm{M}^{-1}\right)$, and $n$ represents the Freundlich exponent, which generally vary in the range of 0.7-1.2 (Banton \& Bangoy 1997) and relates to sorption intensity.

The retardation factors for fracture, fracture-skin and rock-matrix can be modified for nonlinear isotherm and Eqs. (7)-(9) represent the expressions for the same.

$$
\begin{gathered}
R_{f}=1+\frac{K_{f}}{b} n C_{f}^{n-1}, \\
R_{s}=1+\frac{\rho_{s} K_{s}}{\theta_{s}} n C_{s}^{n-1}, \\
R_{m}=1+\frac{\rho_{m} K_{m}}{\theta_{m}} n C_{m}^{n-1} .
\end{gathered}
$$

\section{Initial and boundary conditions}

The initial solute concentration everywhere in the fracture, fracture-skin and rock matrix is assumed to be zero. A constant continuous source is assumed at the upstream boundary of the fracture and a zero flux boundary condition is assumed at the downstream end of the fracture. The downstream boundary is assumed to be far away from the inlet of fracture so that the concentration front will not reach the downstream during simulation time (Renu \& Suresh Kumar 2012). The fluxes at fracture-skin interface and skin-matrix interface are assumed to be continuous to ensure the coupling between fracture, fracture-skin and rock-matrix. Concentration at the fracture-skin interface, i.e., concentrations along the fracture walls and along the lower boundary of the fracture-skin are assumed to be equal and concentrations at the skin-matrix interface, i.e., concentration along the upper boundary of the fracture-skin and lower boundary of the rock-matrix are assumed to be equal.

The initial and boundary conditions associated with Eqs. (1), (3) and (4) are:

$$
\begin{gathered}
C_{f}(x, t=0)=C_{s}(x, y, t=0)=C_{m}(x, y, t=0)=0, \\
C_{f}(x=0, t)=C_{0}, \\
C_{f}\left(x=L_{f}, t\right)=0, \\
C_{f}(x, t)=C_{s}(x, y=b, t), \\
\theta_{s} D_{s} \frac{\partial C_{s}(x, y=d, t)}{\partial y}=\theta_{m} D_{m} \frac{\partial C_{m}(x, y=d, t)}{\partial y} \\
C_{s}(x, y=d, t)=C_{m}(x, y=d, t)
\end{gathered}
$$




$$
\frac{\partial C_{m}(x, y=H, t)}{\partial y}=0,
$$

where $H$ represents the fracture spacing (L), and $L_{f}$ represents the fracture length in $\mathrm{x}$ direction (L).

\section{Numerical method and moment analysis}

In this study, the system of partial differential equations for fracture, fracture-skin and rockmatrix is solved numerically in a one-dimensional framework using second-order central difference finite difference scheme. Uniform grid size is assumed within the fracture and nonuniform grid sizes are assumed within fracture-skin and rock-matrix. Smaller grid sizes are adopted near fracture-skin and skin-matrix interface. The solution is iterated at each time step to satisfy the continuity at the fracture-skin interface. The retardation factors in the fracture, fracture-skin and rock-matrix for all nodes in the coupled fracture-skin-matrix system are computed as nonlinear functions of solute concentration, at each time level, are substituted into the solute transport at current time levels (Suresh Kumar 2008; Renu \& Suresh Kumar 2012). The simulations are carried out starting with small time steps to ensure the accuracy of the results. The results of numerical model are compared with the available analytical solution (Robinson et al 1998). The numerical results are found to be in close agreement with analytical solution for a ranges of values pertaining to fracture, fracture-skin and rock-matrix transport parameters.

In general, the analysis on fluid flow and its associated transport of solutes in a saturated sub-surface fractured formation is generally highly complex in space and time. In addition, the fluid flow in a saturated rock-mass is typically dominated by hyperbolic nature of equations as against the conventional parabolic dominant diffusivity equation, used to describe the fluid flow through a sub-surface system using the macroscopic Darcy's law. Such hyperbolic nature of equations does not allow the physical system to proceed towards a steady-state condition unlike parabolic equations, and subsequently, the concept of transient simulation of flow and transport characteristics becomes inevitable, and temporal moments offer an approach to reduce such time demands of transient simulations. Thus, temporal moments reduce transient governing equations to steady-state and directly simulate the temporal characteristic of the system for linear equations with time-independent coefficients. This reduction is achieved through the integral transformation of zeorth, first and second temporal moments. The zeroth temporal moment represents a simple integral of a response over time, while the first and second temporal moments provide the characteristic response time of the system and square of the characteristic response duration, respectively (Leube et al 2012).

The temporal moment analysis has been shown to be useful for describing solute breakthrough curves (BTC) measured from a solute transport experiment (Rasmuson 1985). Since the resulting Gaussian or bell-shaped BTCs (obtained from numerical modelling) closely match with a probability distribution function (pdf), the statistical properties of the measured breakthrough curve can be used to characterize the behaviour of solute transport processes in a saturated sub-surface system (Govindarajau \& Das 2007).

After obtaining the concentration distribution along the fracture for a coupled fractureskin-matrix system, at each time level, from the above numerical method, the method of temporal moments of lower order for an evolving solute, as a function of space is calculated. Temporal moment estimation has been often used to define the arrival time of a contaminant plume at different distances from source. In addition, temporal moment analysis provides an insight on scale 
dependent characteristics of fracture, skin and rock-matrix parameters as it provides the variation of conventional constant parameters such as velocity and dispersion coefficient as a function of space along the fracture length, while it is to be noted that the each spatial value from the temporal moment analysis represents an average over the time scale of interest. Thus, the information from spatial and temporal moment analyses has different bases. Spatial moment analysis provides better understanding on non-Fickian behaviour of solutes, while temporal moment analysis provides a better understanding on the scale-dependent characteristic nature of constant coefficients used in conventional Advection-Dispersion Equation (ADE).

In the present study, the transport parameters are analysed by computing the zeroth, first, and second temporal moments of concentration distribution along the fracture. Temporal moments can be computed for numerical analysis if concentration data at all time levels are available at a particular location. Such usage of temporal moments is suitable for numerical simulations in the sense that all nodal concentrations in time are available at a given location.

The zeroth moment $\left(\mathrm{M}_{0}\right)$ is proportional to the total aqueous mass of solute within the high permeability fracture, the first temporal moment $\left(\mathrm{M}_{1}\right)$ provides the residence time, second temporal moment $\left(\mathrm{M}_{2}\right)$ describes the spread or deviation about the center of the mass. The method of evaluation of zeroth moment, first moment, second moment, mean $\left(\mathrm{X}_{1}\right)$, variance $\left(\mathrm{X}_{2}\right)$ and space dependant velocity and macro-dispersion coefficient are provided in Eqs. (17)-(26).

$$
M_{0}=\int_{0}^{T} c(x, t) d t
$$

Eq. (17) represents the area underneath the concentration breakthrough curve, which can be estimated by the Simpson's $1 / 3^{\text {rd }}$ rule, which is an extension of Trapezoidal rule, where the integrand is approximated by a second order polynomial.

$$
I=\int_{a}^{b} f(x) d x \approx \int_{a}^{b} f_{2}(x) d x
$$

where $f_{2}(x)$ is a second order polynomial given by

$$
f_{2}(x)=a_{0}+a_{1} x+a_{2} x^{2} .
$$

Since for Simpson's $1 / 3^{\text {rd }}$ rule, the limits of the function are taken between the intervals $a$ and $b$, the segment width becomes

$$
h=\frac{b-a}{2}
$$

Thus, the Simpson's $1 / 3^{\text {rd }}$ rule is given by

$$
\int_{a}^{b} f(x) d x \approx \frac{h}{3}\left[f(a)+4 f\left(\frac{a+b}{2}\right)+f(b)\right] .
$$

The zeroth moment represents the 'effective mass' of the concentration breakthrough curve. The first moment of the breakthrough curve is found by summing the products of the individual zeroth moments and the elapsed time $(\mathrm{t})$ measured to each time step from the beginning of 
solute injection as expressed in Eq. (22). The second temporal moment involves the square of the elapsed time $\left(\mathrm{t}^{2}\right)$ as provided in Eq. (23).

$$
\begin{aligned}
M_{1} & =\int_{0}^{T} t c(x, t) d t, \\
M_{2} & =\int_{0}^{T} t^{2} c(x, t) d t .
\end{aligned}
$$

The first normalized temporal moment is computed as provided in Eq. (24), which represents the mean breakthrough time, i.e., the time when half of the injected mass passed through the location of measurement.

$$
T_{1}(x)=\frac{M_{1}}{M_{0}} .
$$

The second normalized temporal moment is computed as provided in Eq. (25), which represents the degree of mixing of the solute mass within the fracture.

$$
T_{11}(x)=\frac{M_{2}}{M_{0}}-\left[\frac{M_{1}}{M_{0}}\right]^{2} .
$$

From the computed first and second normalized temporal moments, the solute velocity, and the macro-dispersion coefficient can be obtained using the following expressions:

$$
V(x)=\frac{d x}{d\left\{T_{1}(x)\right\}} ; \quad D(x)=\frac{1}{2} \frac{V^{3} d\left\{T_{11}(x)\right\}}{d x},
$$

where $\mathrm{V}(\mathrm{x})$ and $\mathrm{D}(\mathrm{x})$ represent the velocity and macro-dispersion coefficient respectively in the fracture corresponding to a particular location $(\mathrm{x})$ along the fracture.

The expressions for first and second normalized temporal moments (Eqs. 24 and 25) are valid for concentration pulse source. A first derivative of the concentration in the fracture is used to obtain the equivalent pulse of constant continuous source used at the inlet of fracture in order to use Eqs. (17) to (26). From such an analysis, the spatial variation of the effective parameters of the coupled fracture-skin-matrix system such as solute velocity and spreading of solutes along the fracture is assessed.

\section{Results and discussions}

Figure 2 provides the spatial distribution of zeroth temporal moment, which quantifies the total mass in the breakthrough distribution of concentration in a fractured formation in the presence (Cases 3 and 4) and absence (Case 1) of fracture-skin. It is observed from figure 2 that in the absence of fracture-skin and rock-matrix (Case 1) the total mass of solute within the fracture remains equal to $100 \mathrm{mg} / \mathrm{l}$. It is also noted that this mass is distributed uniformly throughout the entire length of the fracture at a rate of $1 \mathrm{mg} / \mathrm{l}$, which is equal to that of the concentration at the inlet, and subsequently represents that there is no mass transfer either into fracture-skin or rock-matrix associated with it. However, the mass distribution within the fracture in the presence of fracture-skin is no more uniform within the fracture and the mass distribution varies linearly 


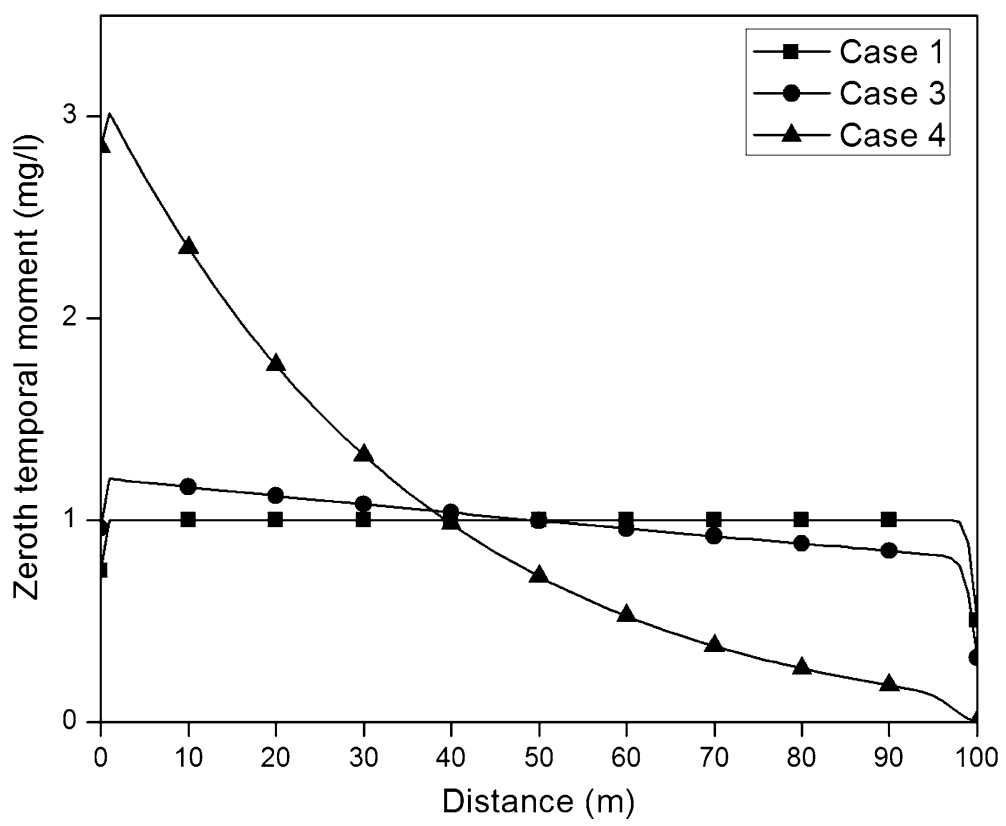

Figure 2. Spatial distribution of zeroth temporal moment for a coupled fracture-skin-matrix system. Refer table 1 for base case parameters. (Case 1: Fracture only; Case 3: $\theta_{s}=0.00145$; Case 4: $\theta_{s}=0.0145$ ).

within the fracture with a relatively low fracture-skin thickness (Case 3), while the mass distribution within the fracture varies nonlinearly (similar to that of an exponential decay) for a relatively larger fracture-skin thickness (Case 4). However, it can be noted that the total mass of solute in all these cases remain the same at $100 \mathrm{mg} / \mathrm{l}$. It is observed from figure 2 that the mass accumulation nearer to the fracture inlet is very high (nearly $3 \mathrm{mg} / \mathrm{l} @ 1 \mathrm{~m}$ ), while the same is

Table 1. Base case parameters [basic dataset taken from Robinson et al (1998)].

\begin{tabular}{ll}
\hline Variable & Skin 1 \\
\hline Average fluid flow velocity in fracture $\left(\mathrm{V}_{0}\right)$ & $1.0 \mathrm{~m} / \mathrm{d}$ \\
Fracture dispersivity $(\alpha)$ & $0.001 \mathrm{~m}$ \\
Longitudinal dispersion coefficient within the fracture $(\mathrm{L})$ & $1 \times 10^{-3} \mathrm{~m}^{2} / \mathrm{d}$ \\
Free molecular diffusion coefficient in water $\left(\mathrm{D}^{*}\right)$ & $1 \times 10^{-6} \mathrm{~m}^{2} / \mathrm{d}$ \\
Effective diffusion coefficient in the rock-matrix $(\mathrm{D} m)$ & $4 \times 10^{-6} \mathrm{~m}^{2} / \mathrm{d}$ \\
Effective diffusion coefficient in the fracture-skin $(\mathrm{D} s)$ & $4 \times 10^{-7} \mathrm{~m}^{2} / \mathrm{d}$ \\
Porosity of fracture-skin $\left(\theta_{s}\right)$ & 0.0145 \\
Porosity of rock-matrix $\left(\theta_{m}\right)$ & 0.145 \\
Length of fracture $\left(\mathrm{L}_{f}\right)$ & $150 \mathrm{~m}$ \\
Fracture pacing $(2 \mathrm{H})$ & $0.31 \mathrm{~m}$ \\
Half fracture aperture $(\mathrm{b})$ & $0.0002 \mathrm{~m}$ \\
Skin thickness $(\mathrm{d}-\mathrm{b})$ & $0.0018 \mathrm{~m}$ \\
Radioactive decay $(\lambda)$ & $0.0 \mathrm{~d}-1$ \\
Cell width $(\Delta \mathrm{x})$ & $0.001 \mathrm{~m}$ \\
Time step $(\Delta \mathrm{t})$ & $0.005 \mathrm{~d}$ \\
Total simulation time $(\mathrm{TST})$ & $100 \mathrm{days}$ \\
\hline
\end{tabular}


Table 2. Variation of parameters in different cases.

\begin{tabular}{|c|c|c|c|c|c|c|c|}
\hline Parameter & $\begin{array}{l}\text { Skin } \\
\text { porosity } \\
\left(\theta_{S}\right)\end{array}$ & $\begin{array}{l}\text { Eff. diffusion } \\
\text { coefficient } \\
\text { in skin } \\
\left(\mathrm{D}_{s}\left(\mathrm{~m}^{2} / \mathrm{d}\right)\right)\end{array}$ & $\begin{array}{l}\text { Matrix } \\
\text { porosity } \\
\left(\theta_{m}\right)\end{array}$ & $\begin{array}{l}\text { Eff. diffusion } \\
\text { coefficient } \\
\text { in matrix } \\
\left(\mathrm{D}_{m}\left(\mathrm{~m}^{2} / \mathrm{d}\right)\right)\end{array}$ & $\begin{array}{l}\text { Fracture } \\
\text { skin } \\
\text { thickness } \\
(\mathrm{d}-\mathrm{b}(\mathrm{m}))\end{array}$ & $\begin{array}{l}\text { Radioactive } \\
\text { decay } \\
(\lambda(/ \mathrm{d}))\end{array}$ & $\begin{array}{l}\text { Sorption } \\
\text { intensity } \\
\text { (n) }\end{array}$ \\
\hline Case 1 & $\mathbf{0}$ & 0 & 0 & 0 & 0 & 0 & 0 \\
\hline Case 2 & 0 & 0 & 0.145 & $4 * 10^{-6}$ & 0 & 0 & 0 \\
\hline Case 3 & 0.00145 & $4 * 10^{-7}$ & 0.145 & $4 * 10^{-6}$ & 0.0018 & 0 & 0 \\
\hline Case 4 & 0.0145 & $4 * 10^{-7}$ & 0.145 & $4 * 10^{-6}$ & 0.0018 & 0 & 0 \\
\hline Case 5 & 0.145 & $4 * 10^{-7}$ & 0.145 & $4 * 10^{-6}$ & 0.0018 & 0 & 0 \\
\hline Case 6 & 0.00145 & $4 * 10^{-7}$ & 0.145 & $4 * 10^{-6}$ & 0.0005 & 0 & 0 \\
\hline Case 7 & 0.00145 & $4 * 10^{-7}$ & 0.145 & $4 * 10^{-6}$ & 0.001 & 0 & 0 \\
\hline Case 8 & 0.00145 & $4 * 10^{-7}$ & 0.145 & $4 * 10^{-6}$ & 0.05 & 0 & 0 \\
\hline Case 9 & 0.145 & $4 * 10^{-7}$ & 0.145 & $4 * 10^{-6}$ & 0.0005 & 0 & 0 \\
\hline Case 10 & 0.145 & $4 * 10^{-7}$ & 0.145 & $4 * 10^{-6}$ & 0.001 & 0 & 0 \\
\hline Case 11 & 0.145 & $4 * 10^{-7}$ & 0.145 & $4 * 10^{-6}$ & 0.05 & 0 & 0 \\
\hline Case 12 & 0.0145 & $4 * 10^{-7}$ & 0.145 & $4 * 10^{-6}$ & 0.0018 & 0 & 0 \\
\hline Case 13 & 0.00145 & $4 * 10^{-8}$ & 0.145 & $4 * 10^{-6}$ & 0.0018 & 0 & 0 \\
\hline Case 14 & 0.0145 & $4 * 10^{-7}$ & 0.00145 & $4 * 10^{-8}$ & 0.0018 & 0 & 0 \\
\hline Case 15 & 0.145 & $4 * 10^{-6}$ & 0.00145 & $4 * 10^{-8}$ & 0.0018 & 0 & 0 \\
\hline Case 16 & 0.145 & $4 * 10^{-6}$ & 0.145 & $4 * 10^{-6}$ & 0.0018 & 0 & 0.8 \\
\hline Case 17 & 0.145 & $4 * 10^{-6}$ & 0.145 & $4 * 10^{-6}$ & 0.0018 & 0 & 1.0 \\
\hline Case 18 & 0.145 & $4 * 10^{-6}$ & 0.145 & $4 * 10^{-6}$ & 0.0018 & 0 & 1.2 \\
\hline Case 19 & 0 & 0 & 0 & 0 & 0 & 0.05 & 0 \\
\hline Case 20 & $\mathbf{0}$ & $\mathbf{0}$ & 0.145 & $4 * 10^{-6}$ & 0 & 0.05 & 0 \\
\hline Case 21 & 0.145 & $4 * 10^{-7}$ & 0.145 & $4 * 10^{-6}$ & 0.0018 & 0.05 & 0 \\
\hline
\end{tabular}

very low (nearly $0 \mathrm{mg} / \mathrm{l} @ 100 \mathrm{~m}$ ) towards the outlet in the presence of fracture-skin with significant thickness (Case 4). This implies that a large diffusive mass transfer will be associated towards the inlet, while there is no opportunity for diffusive mass transport at all towards the outlet as the associated mass distribution towards the outlet is nearly zero. It can be concluded from figure 2 that the total mass of solute in a coupled fracture-skin-matrix system is conserved in the absence of radioactive decay (table 2).

Figure 3 provides the spatial distribution of first temporal moment (mean arrival time) for different values of fracture-skin porosities. It is observed from figure 3 that in the absence of fracture-skin and rock-matrix (Case 1) the mean arrival time of solute in the fracture varies linearly and from the slope of the profile it can be seen that the solute velocity along the fracture is $1 \mathrm{~m}$ /day and is equal to the fluid velocity. Whereas in case of a coupled fracture-matrix system (Case 2), the variation of mean arrival time along the fracture is nonlinear and the slope of the profile is decreasing as the distance from the source increases and finally it tends to approach zero (at the end of $80 \mathrm{~m}$ in figure 3). Further it can be noted from figure 3 that in case of coupled fracture-skin-matrix system with low fracture-skin porosity (Cases 3 and 4), the mean arrival time is linearly varying along the fracture. It can be observed from figure 3 that in a coupled fracture-skin-matrix system with low porosity fracture-skin, the solute velocity along the fracture is constant. In the case of high fracture-skin porosity (Case 3) slope of the profiles is constant near the source and slope of curve is becoming zero away from the source (at the end of $100 \mathrm{~m}$ in figure 3 ) which indicates that the solute velocity along the fracture is constant near the source and solute velocity is becoming zero away from the source. 


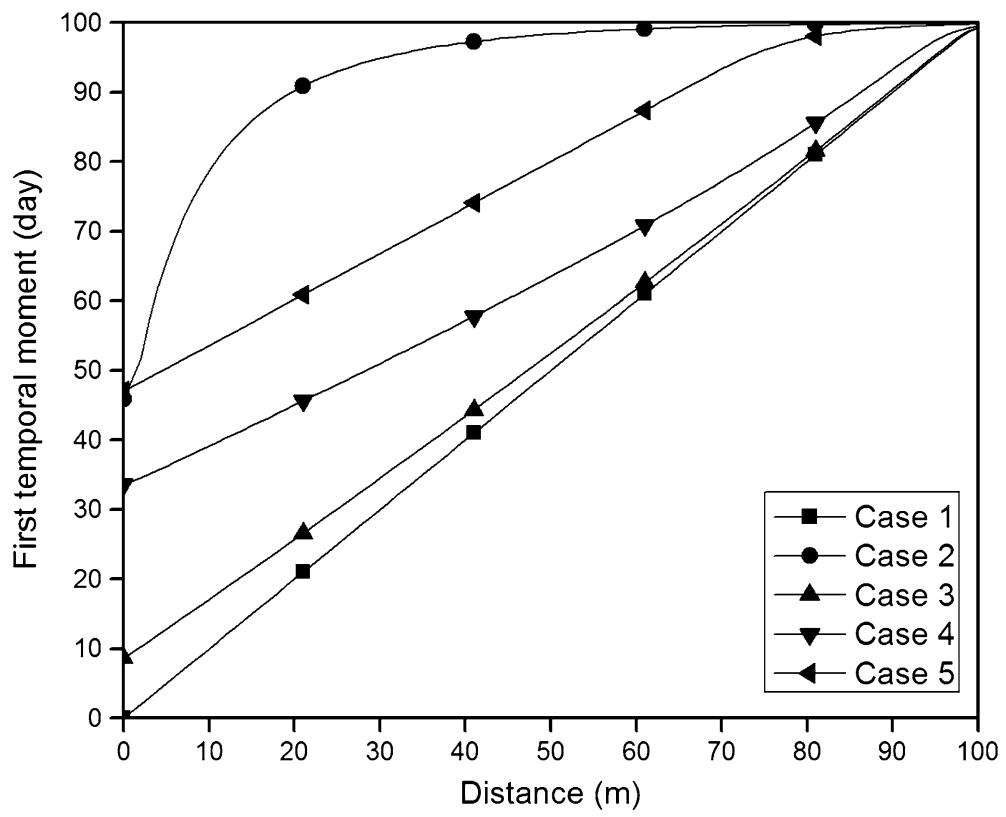

Figure 3. Spatial distribution of first temporal moment for a coupled fracture-skin-matrix system. Refer table 1 for base case parameters. (Case 1: Fracture only; Case 2: Fracture-Matrix; Case 3: $\theta_{s}=0.00145$; Case 4: $\theta_{s}=0.0145$, Case 5: $\left.\theta_{s}=0.145\right)$.

Figure 4 provides spatial distribution of second temporal moment (variance of the mean arrival time) for same data set as given in figure 3. It can be seen from figure 4 that value of the second temporal moment increases nonlinearly in both coupled fracture-matrix system (Case 2) and in coupled fracture-skin-matrix system (Cases 3, 4 and 5) which indicates that the magnitude of solute dispersion coefficient is scale dependant in both the cases. Magnitude of dispersion coefficient of solutes can be computed from the slope of the profiles using Eq. (19). It can be observed from figure 4 that the presence of fracture-skin may reduce or increase quantum of dispersion in comparison to that in a coupled fracture-matrix system depending on porosity of fracture-skin. Presence of high porosity fracture-skin will enhance solute spreading whereas presence of low porosity fracture-skin will reduce of solute spreading. In all cases shown in figure 4 quantum of dispersion is very large near the fracture inlet and reduces exponentially along the fracture.

Figure 5 provides the spatial distribution of first temporal moment for a coupled fractureskin-matrix system for a range of fracture-skin thicknesses under very low fracture-skin porosity $\left(\theta_{s}=0.00145\right)$. It can be observed from figure 5 that the mean arrival time is increasing linearly along the fracture for all cases of fracture-skin thickness and the solute velocity remains constant along the fracture in all the three cases of fracture-skin thickness. It implies that under very low fracture-skin porosity, velocity of solute is not scale dependant and mobility of solute is not sensitive to thickness of fracture-skin. Figure 6 provides spatial distribution of second temporal moment for same data sets as seen in figure 5. It can be noted from figure 6 that under low fracture-skin porosity solute spreading is sensitive to thickness of fracture-skin. In all three cases shown in figure 6, slope of profiles are very large near the source and is becoming zero away 


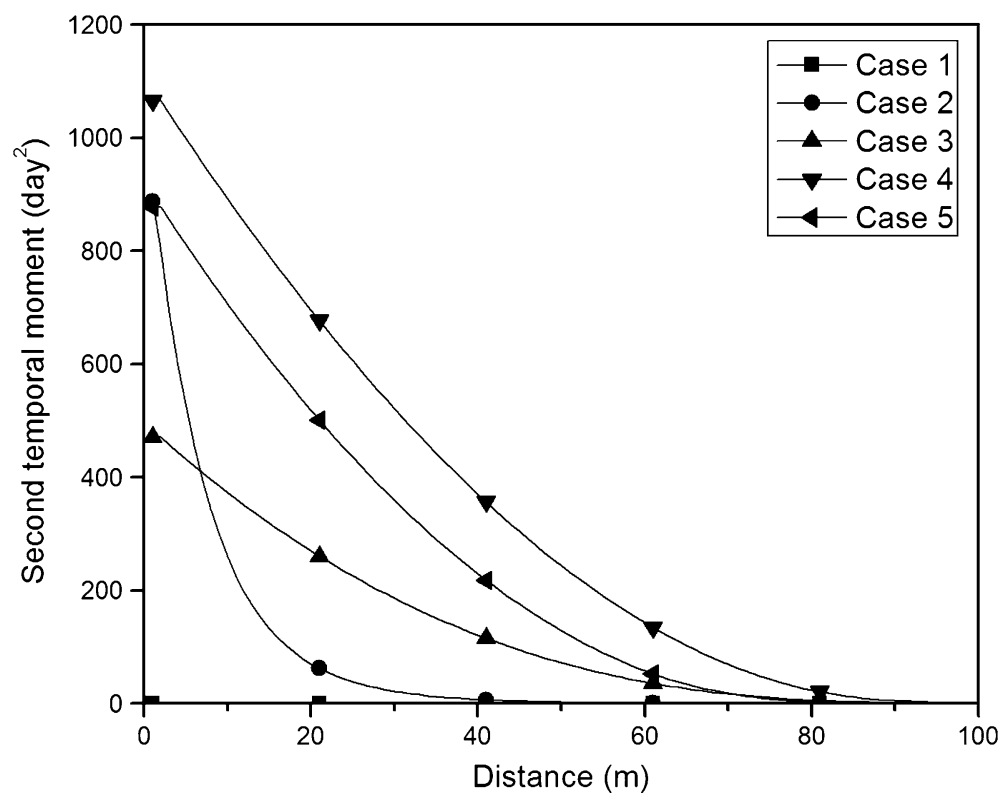

Figure 4. Spatial distribution of second temporal moment for a coupled fracture-skin-matrix system. Refer table 1 for base case parameters (Case 1: Fracture only; Case 2: Fracture-Matrix; Case 3: $\theta_{s}=$ 0.00145; Case 4: $\theta_{s}=0.0145$, Case 5: $\theta_{s}=0.145$ ).

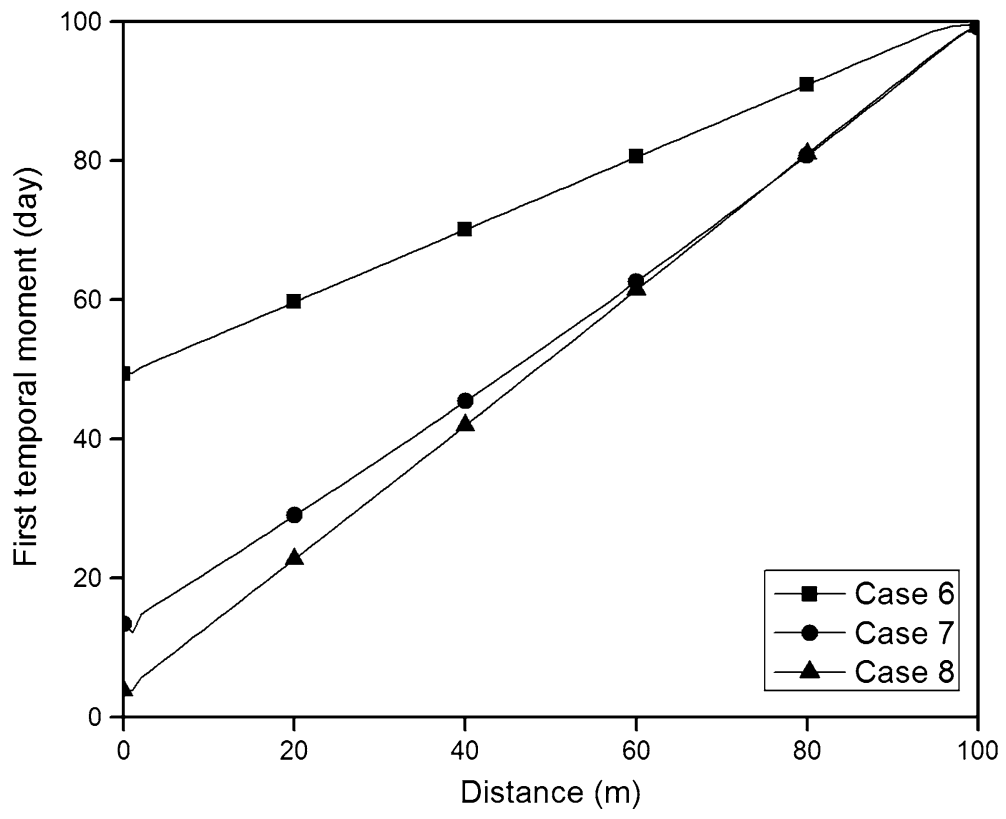

Figure 5. Spatial distribution of first temporal moment for a coupled fracture-skin-matrix system. $\theta_{s}=$ 0.00145 , refer table 1 for base case parameters (Case 6: $(d-b)=0.0005 \mathrm{~m}$; Case 7: $(d-b)=0.001 \mathrm{~m}$; Case $8:(\mathrm{d}-\mathrm{b})=0.05 \mathrm{~m})$. 


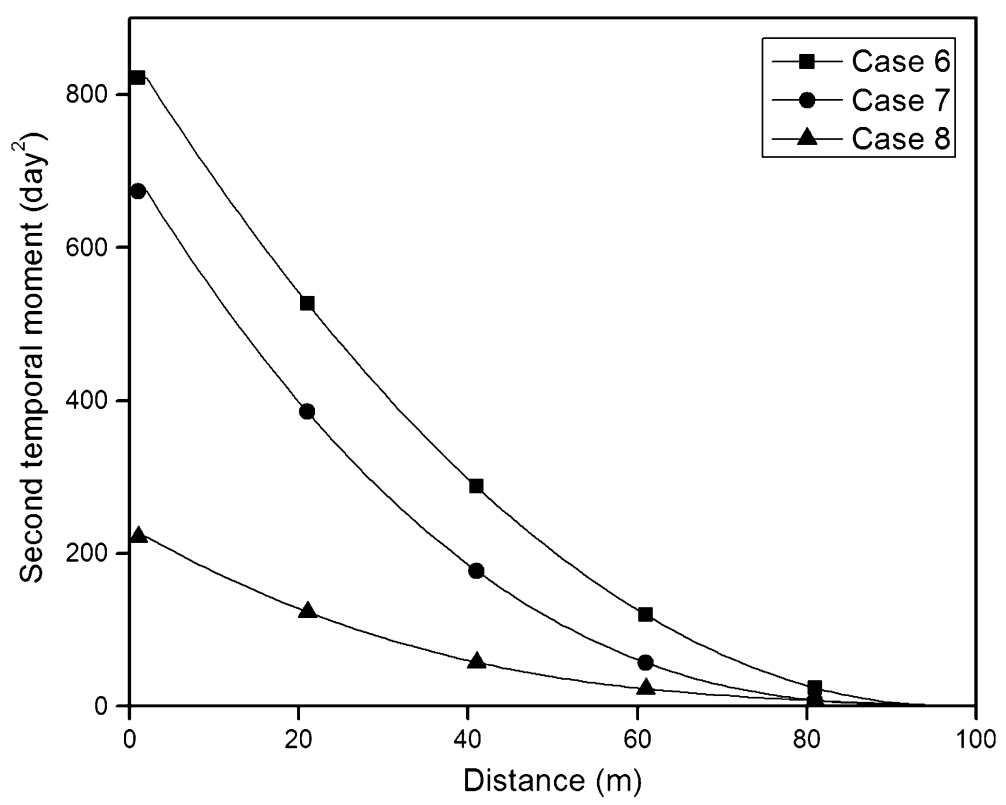

Figure 6. Spatial distribution of second temporal moment for a coupled fracture-skin-matrix system. $\theta_{s}=$ 0.00145, refer table 1 for base case parameters (Case 6: $(d-b)=0.0005 \mathrm{~m}$; Case 7: $(d-b)=0.001 \mathrm{~m}$; Case $8:(\mathrm{d}-\mathrm{b})=0.05 \mathrm{~m})$.

from fracture inlet. Further, it can be noted from figure 6 that the solute spreading reduces with increase in fracture-skin thickness.

Figure 7 provides the spatial variation of first temporal moment for fracture-skin thicknesses varying over two orders of magnitude under high fracture-skin porosity. It can be observed from figure 7 that in case of low fracture-skin thickness (Cases 9 and 10), the mean arrival time of solute is varying linearly along the fracture and the solute velocity remains constant whereas in case of high fracture-skin thickness (Case 11), the mean arrival time is showing a nonlinear variation along the fracture. In case of high fracture-skin thickness solute velocity is more near the source and it reduces to zero away from source. It implies that under high fracture-skin porosity, solute velocity is sensitive to thickness of fracture-skin and under high fracture-skin porosity and large fracture-skin thickness; solute mobility scale dependant. Figure 8 provides spatial distribution of second spatial moment for same data sets as seen in figure 7 . It can be seen from figure 8 that under very high fracture-skin porosity, for all three cases of fracture-skin thicknesses the second temporal moment shows a nonlinear variation along the fracture and the magnitude of dispersion coefficient is not sensitive to thickness of fracture-skin. Further, it can be noted from figure 8 that the quantum of dispersion is very huge near the fracture inlet and it exponentially reduces as distance from source increases.

Figure 9 provides spatial distribution of first temporal moment when properties of rock-matrix $\left(\theta_{m}\right.$ and $\left.\mathrm{D}_{m}\right)$ have larger magnitude than that of its associated fracture-skin $\left(\theta_{s}\right.$ and $\left.\mathrm{D}_{s}\right)$. Case 12 in figure 9 corresponds to the case parameters or rock matrix $\left(\mathrm{D}_{m}\right.$ and $\left.\theta_{m}\right)$ are slightly larger than that of fracture-skin whereas Case 13 corresponds to the case in which parameters of rockmatrix are significantly higher than that of fracture-skin. It is observed from figure 9 that mean arrival time is showing a linear variation indicating a constant velocity of solutes along the fracture in both the cases and from the figure it can be inferred that the solute velocity is not 


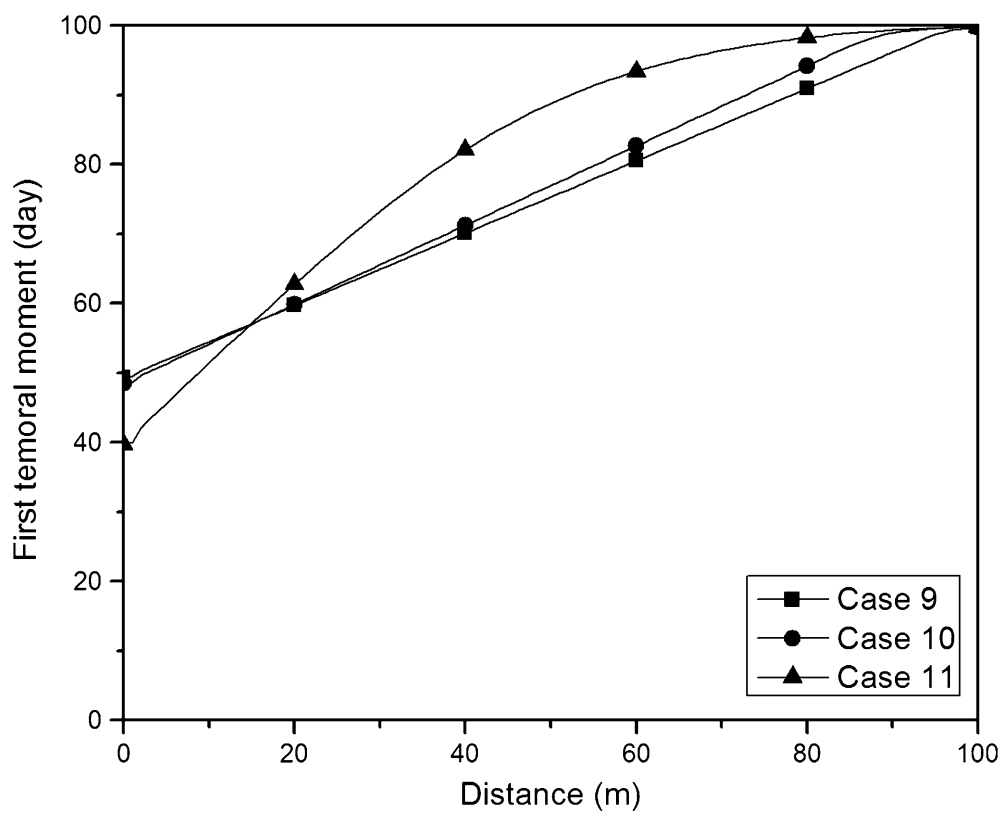

Figure 7. Spatial distribution of first temporal moment for a coupled fracture-skin-matrix system. $\theta_{s}=$ 0.145 , refer table 1 for base case parameters (Case 9: $(d-b)=0.0005 \mathrm{~m}$; Case 10: $(d-b)=0.001 \mathrm{~m}$; Case 11 : $(\mathrm{d}-\mathrm{b})=0.05 \mathrm{~m})$.

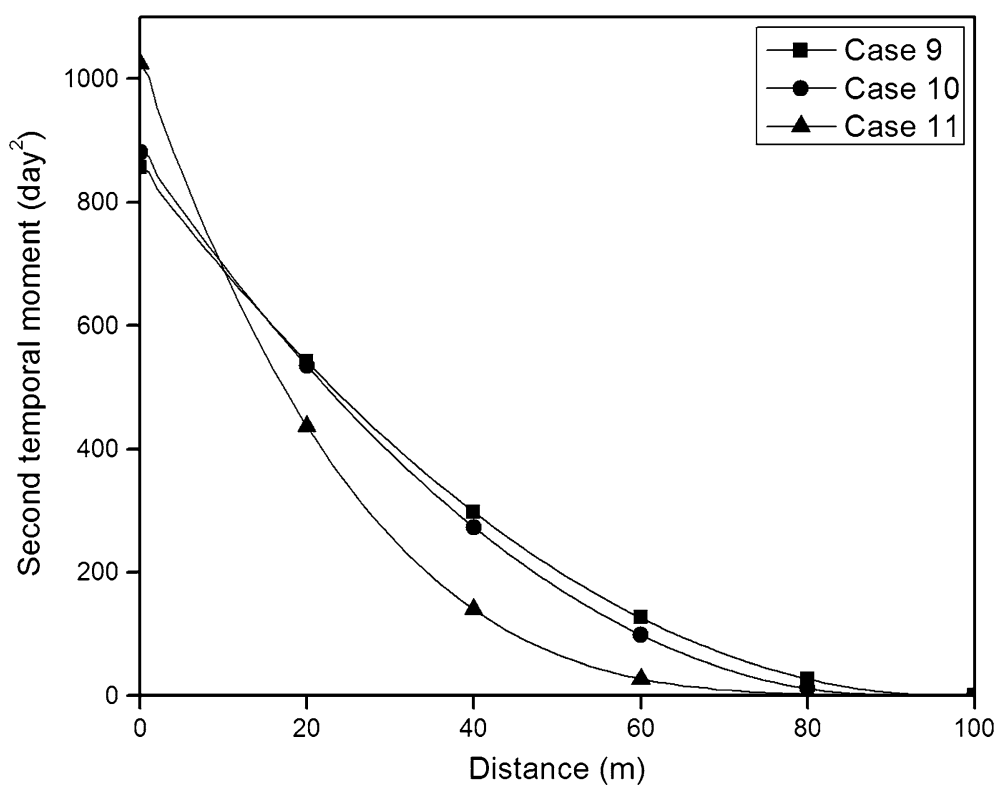

Figure 8. Spatial distribution of second temporal moment for a coupled fracture-skin-matrix system. $\theta_{s}=$ 0.145 , refer table 1 for base case parameters (Case 9: $(d-b)=0.0005 \mathrm{~m}$; Case 10: $(d-b)=0.001 \mathrm{~m}$; Case 11: $(\mathrm{d}-\mathrm{b})=0.05 \mathrm{~m}$. 


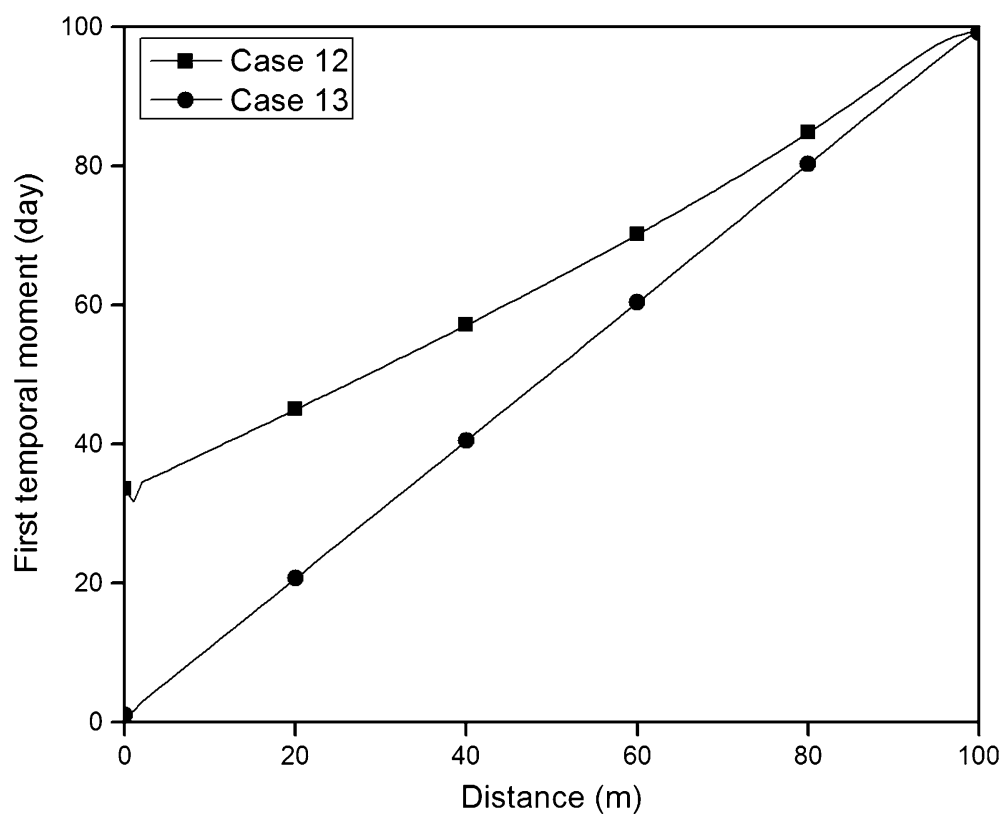

Figure 9. Spatial distribution of first temporal moment for a coupled fracture-skin-matrix system. $\mathrm{D}_{m}=$ $4 \times 10^{-6} \mathrm{~m}^{2} / \mathrm{d}, \theta_{m}=0.145$, refer table 1 for base case parameters (Case $12: \mathrm{D}_{s}=4 \times 10^{-7} \mathrm{~m}^{2} / \mathrm{d}$, $\theta_{s}=0.0145 ;$ Case 13: $\left.\mathrm{D}_{s}=\times 10^{-8} \mathrm{~m}^{2} / \mathrm{d}, \theta_{s}=0.00145\right)$.

sensitive to fracture-skin parameters $\left(\mathrm{D}_{s}\right.$ and $\left.\theta_{s}\right)$ when parameters of rock-matrix $\left(\mathrm{D}_{m}\right.$ and $\left.\theta_{m}\right)$ have large magnitude compared to that of fracture-skin $\left(\mathrm{D}_{s}\right.$ and $\left.\theta_{s}\right)$. Figure 10 provides spatial distribution of second temporal moment for same data sets as seen in figure 9 . It can be observed from figure 10 that when parameters of rock-matrix are slightly higher than that of fracture-skin (Case 12), magnitude of solute dispersion coefficient is very huge near the source and it reduces exponentially and is becoming zero away from the source whereas when parameters of rockmatrix are significantly higher than that of fracture-skin spreading of solute along the fracture is very less. From figure 10 it can be inferred that spreading of solutes is highly sensitive to fracture-skin parameters $\left(\mathrm{D}_{s}\right.$ and $\left.\theta_{s}\right)$ when parameters of rock-matrix $\left(\mathrm{D}_{m}\right.$ and $\left.\theta_{m}\right)$ have slightly large magnitude compared to that of fracture-skin $\left(\mathrm{D}_{s}\right.$ and $\left.\theta_{s}\right)$.

Figure 11 provides the spatial distribution of first temporal moment when properties of fracture-skin $\left(\theta_{s}\right.$ and $\left.\mathrm{D}_{s}\right)$ have higher magnitude in comparison with that of the surrounding rock-matrix. It can be observed from figure 11 that in both the cases, the mean arrival time shows a linear variation indicating a constant velocity along the fracture and when the properties of fracture-skin are significantly greater than the surrounding rock-matrix (Case 15), the solute velocity is getting retarded considerably along the fracture and velocity is reaching zero away from the source. Figure 12 provides spatial distribution of second temporal moment for a coupled fracture-skin-matrix system for the same data sets as seen in figure 11. It can be noted from figure 12 that in both the cases, magnitude of dispersion coefficient reduces with increase of distance along the fracture and becomes zero away from the source. From the figure 12 it can be inferred that the second temporal moment is not much sensitive to fracture skin parameters when properties of fracture-skin $\left(\theta_{s}\right.$ and $\left.\mathrm{D}_{s}\right)$ have higher magnitude in comparison with that of the surrounding rock-matrix. 


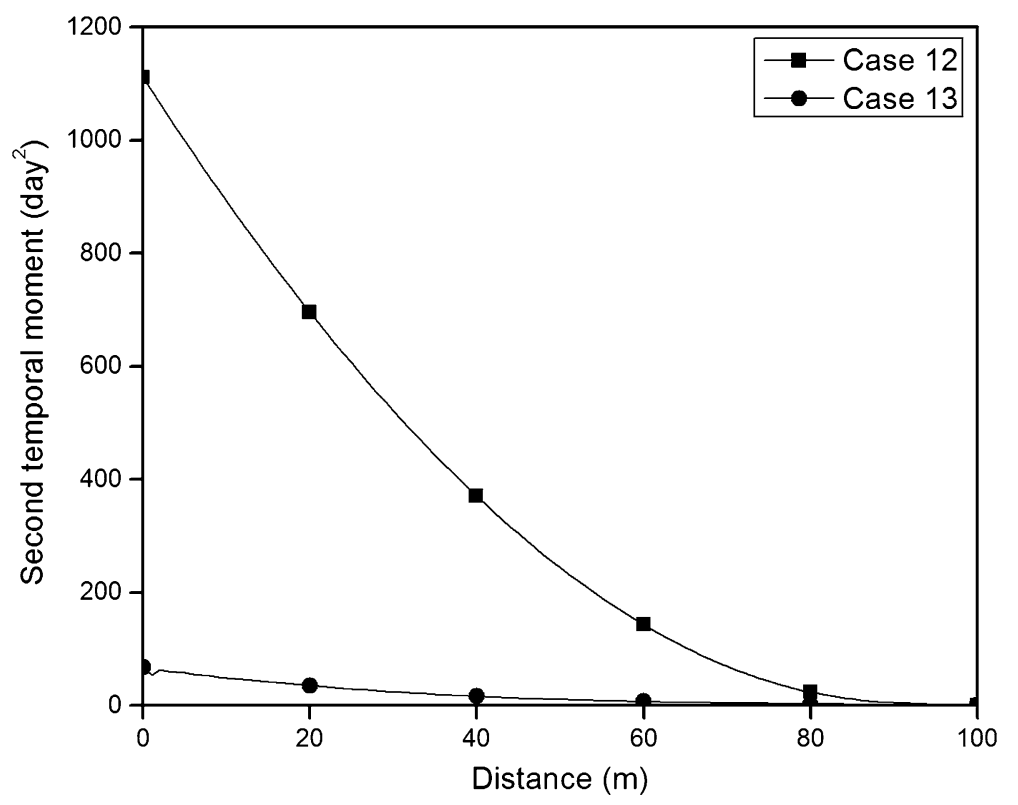

Figure 10. Spatial distribution of second temporal moment for a coupled fracture-skin-matrix system. $\mathrm{D}_{m}=4 \times 10^{-6} \mathrm{~m}^{2} / \mathrm{d}, \theta_{m}=0.145$, refer table 1 for base case parameters (Case $12: \mathrm{D}_{s}=4 \times 10^{-7} \mathrm{~m}^{2} / \mathrm{d}$, $\theta_{s}=0.0145 ;$ Case 13: $\left.\mathrm{D}_{s}=4 \times 10^{-8} \mathrm{~m}^{2} / \mathrm{d}, \theta_{s}=0.00145\right)$.

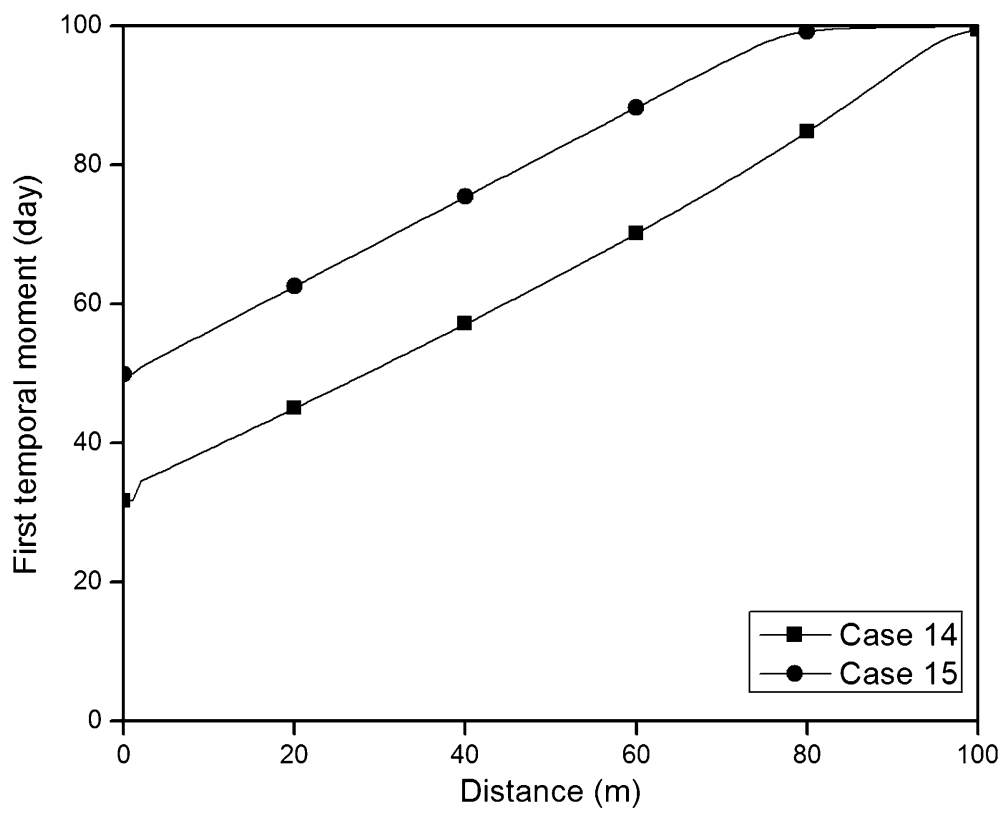

Figure 11. Spatial distribution of first temporal moment for a coupled fracture-skin-matrix system. $\mathrm{D}_{m}=$ $4 \times 10^{-8} \mathrm{~m}^{2} / \mathrm{d}, \theta_{m}=0.00145$, refer table 1 for base case parameters (Case $14: \mathrm{D}_{s}=4 \times 10^{-7} \mathrm{~m}^{2} / \mathrm{d}$, $\theta_{s}=0.0145 ;$ Case 15: $\left.\mathrm{D}_{s}=4 \times 10^{-6} \mathrm{~m}^{2} / \mathrm{d}, \theta_{s}=0.145\right)$. 


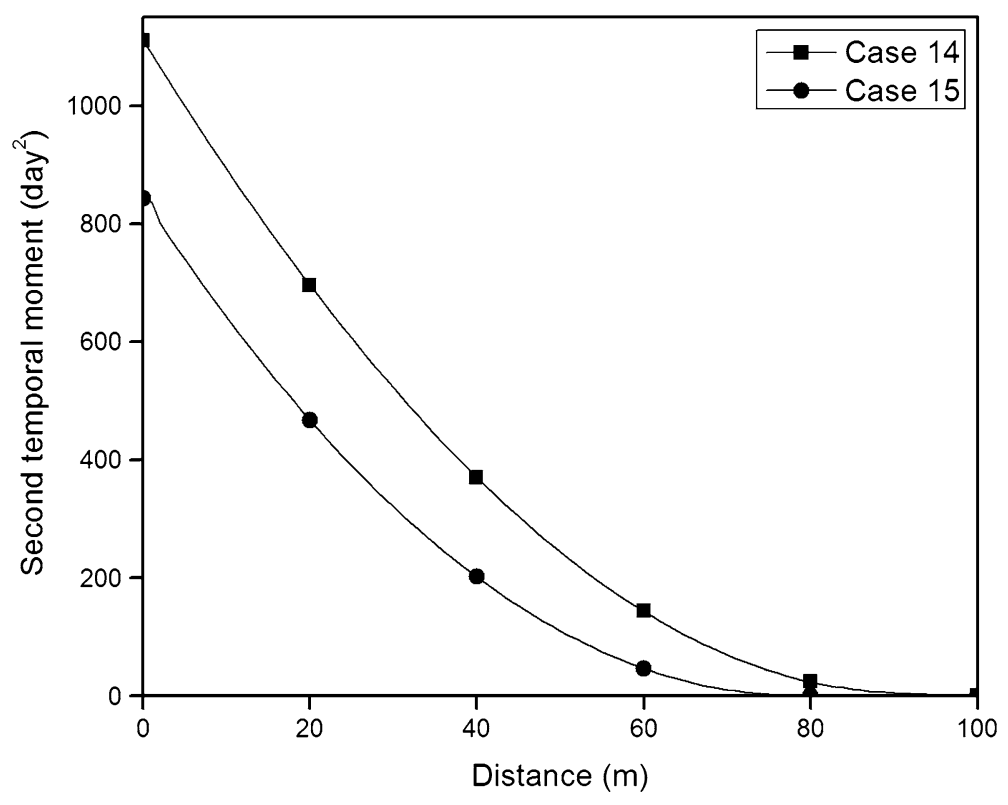

Figure 12. Spatial distribution of second temporal moment for a coupled fracture-skin-matrix system. $\mathrm{D}_{m}=4 \times 10^{-8} \mathrm{~m}^{2} / \mathrm{d}, \theta_{m}=0.00145$, refer table 1 for base case parameters (Case $14: \mathrm{D}_{s}=4 \times 10^{-7} \mathrm{~m}^{2} / \mathrm{d}$, $\theta_{s}=0.0145 ;$ Case 15: $\left.\mathrm{D}_{s}=4 \times 10^{-6} \mathrm{~m}^{2} / \mathrm{d}, \theta_{s}=0.145\right)$.

Figure 13 provides spatial distribution of first temporal moment under high skin porosity $\left(\theta_{s}=\right.$ 0.145 ) for sorption intensities varying from 0.8 to 1.2 . It can be observed from figure 13 that for all cases of sorption intensities profile obtained are nonlinear, which indicates non uniform solute velocity along the fracture. It can be seen from the figure that near the source, slope of the profile is more hence solute velocity is more, and as the distance from the inlet increases solute velocity is getting retarded. Further it can be observed from figure 13 that as the sorption intensity increases the solute velocity will reach zero closer to the source and it can be inferred from the figure that in a coupled fracture-skin-matrix system under nonlinear sorption, solute mobility is a function of space. Figure 14 provides spatial distribution of second temporal moment for a coupled fracture-skin-matrix for same data sets seen in figure 13. It can be noted from figure 14 that profiles obtained are similar in case of both linear and nonlinear sorption and implies that the solute spreading as a function of space is not sensitive to the sorption intensities. Further, it can be noted from figure 14 that spreading of the solute is more near the source and approaches zero as the distance from source increases.

Figure 15 provides spatial distribution of first temporal moment for radioactive decay. Case 19 represents the profile, when decay is considered within the fracture in the absence of fracture-skin and rock-matrix. Case 20 represents the profile when decay is considered in a fracture-matrix coupled system in the absence of fracture-skin. Case 21 represents the profile when decay is considered in a coupled fracture-skin-matrix system. It can be noted from figure 15 that the profile is linear when decay is considered in a fracture and in a fracture-skin-matrix coupled system. Profile is nonlinear in a fracture-matrix coupled system, with a high solute velocity very nearer to the source and zero solute velocity away from the source. This implies that solute velocity in a coupled fracture-matrix system is scale dependant. Figure 16 provides spatial distribution of second temporal moment for same data set as shown in figure 15. It can be 


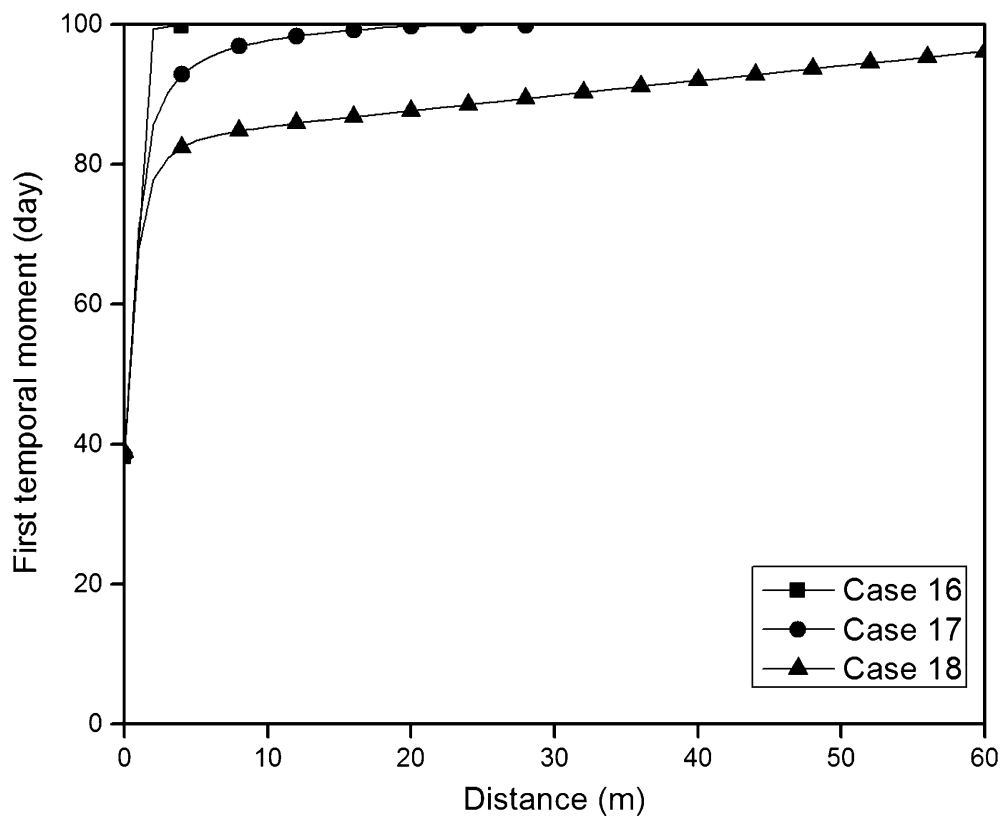

Figure 13. Spatial distribution of first temporal moment for a coupled fracture-skin matrix system. $\left(K_{f} /\right.$ $b)=6,\left(\rho_{s} K_{s} / \theta_{s}\right)=699,\left(\rho_{m} K_{m} / \theta_{m}\right)=69, \mathrm{D}_{s}=4 \times 10^{-6} \mathrm{~m}^{2} / \mathrm{d}, \theta_{s}=0.145$, refer table 1 for base case parameters (Case 16: $\mathrm{n} \mathrm{e}=0.8$; Case 17: $\mathrm{n}=1.0$; Case 18: $\mathrm{n}=1.2$ ).

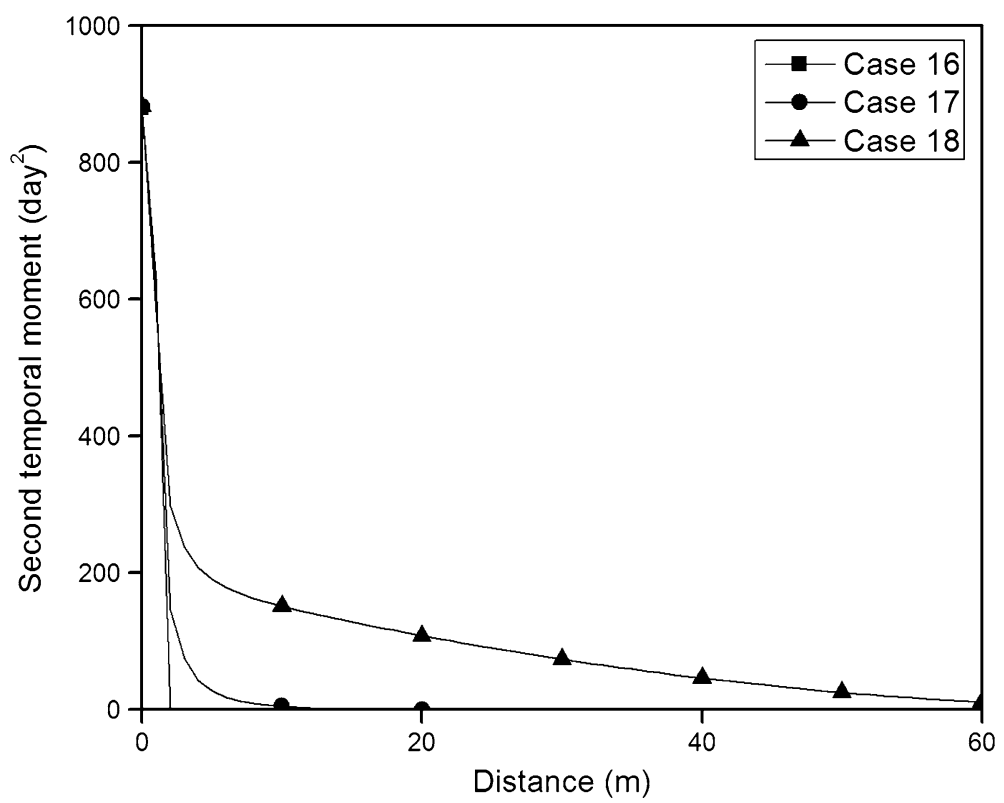

Figure 14. Spatial distribution of second temporal moment for a coupled fracture-skin matrix system. $\left(K_{f} / b\right)=6,\left(\rho_{s} K_{s} / \theta_{s}\right)=699,\left(\rho_{m} K_{m} / \theta_{m}\right)=69, \mathrm{D}_{s}=4 \times 10^{-6} \mathrm{~m}^{2} / \mathrm{d}, \theta_{s}=0.145$, refer table 1 for base case parameters (Case 16: $\mathrm{n}=0.8$; Case 17: $\mathrm{n}=1.0$; Case 18: $\mathrm{n}=1.2$ ). 


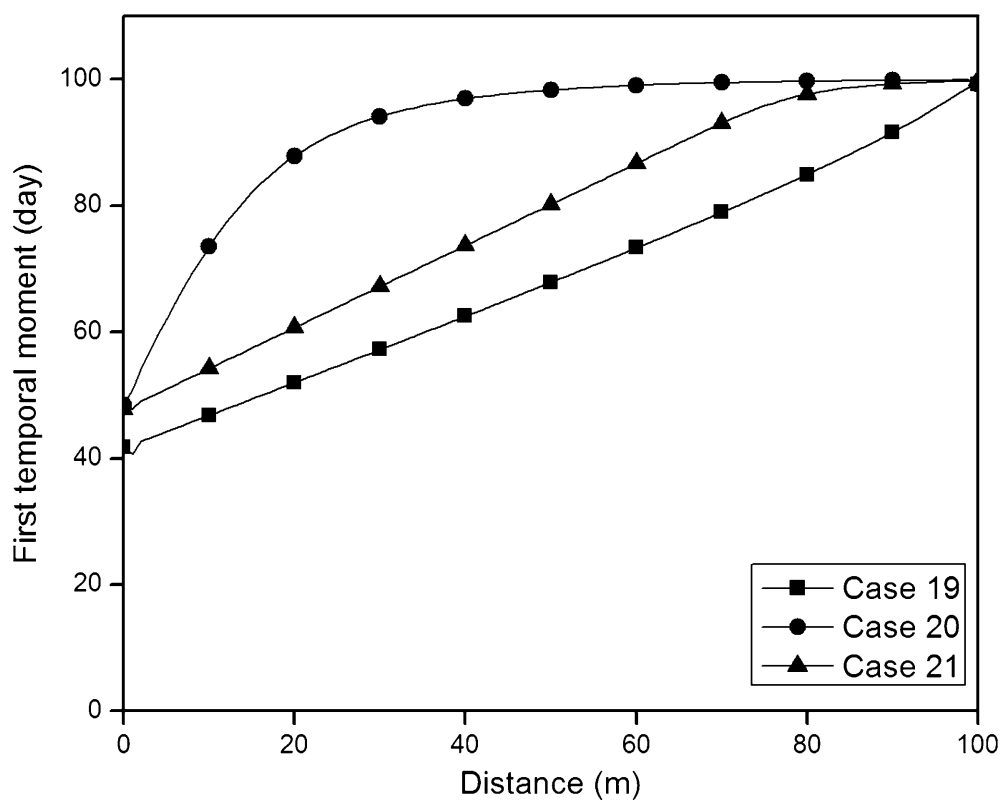

Figure 15. Spatial distribution of first temporal moment for a coupled fracture-skin-matrix system. $\lambda=$ $0.05 / \mathrm{d}$, refer table 1 for base case parameters (Case 19: Fracture only; Case 20: Fracture-matrix; Case 21: $\left.\theta_{s}=0.145\right)$.

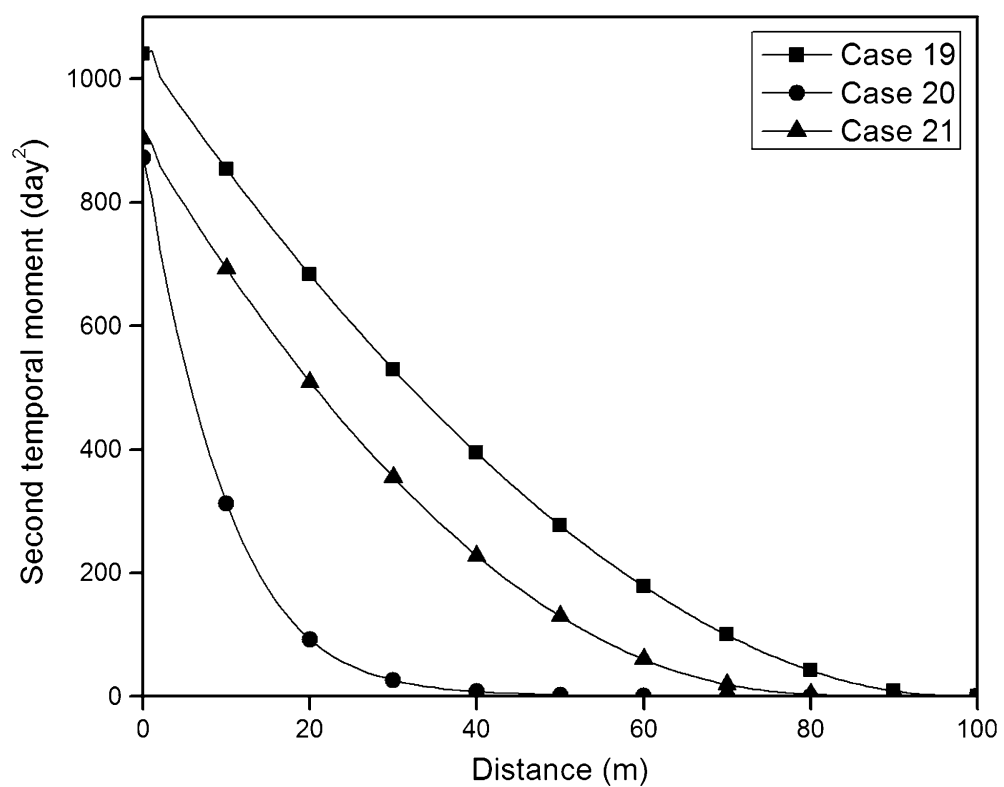

Figure 16. Spatial distribution of second temporal moment for a coupled fracture-skin-matrix system. $\lambda=0.05 / \mathrm{d}$, refer table 1 for base case parameters (Case 19: Fracture only; Case 20: Fracture-matrix; Case 21: $\left.\theta_{s}=0.145\right)$. 
noted from figure 16 that under radioactive decay spreading of solute is not affected by the presence of fracture-skin. From figure 16 it can be inferred that in a coupled fracture-matrix system (Case 21), the spreading of solutes is more near the source and it reaches zero very nearer to the source compared to the spreading of solutes in a coupled fracture-skin-matrix system.

\section{Summary and conclusions}

In this study, numerical simulation is carried out along with temporal moment analysis to study the influence of fracture skin on solute breakthrough curve of a solute in a coupled fracture-skinmatrix system. The study is conducted in a one-dimensional framework for a boundary condition of constant continuous source at the inlet and a constant flow velocity is assumed within the fracture. Findings of the study can be summarized as follows:

(i) When properties of rock-matrix $\left(\theta_{m}\right.$ and $\left.\mathrm{D}_{m}\right)$ have larger magnitude than that of its associated fracture-skin $\left(\theta_{s}\right.$ and $\left.\mathrm{D}_{s}\right)$, the solute mobility is not dependant on the fracture-skin properties where as spreading of the solutes is dependent on fracture-skin properties.

(ii) When properties of fracture-skin $\left(\theta_{s}\right.$ and $\left.\mathrm{D}_{s}\right)$ have higher magnitude in comparison with that of the surrounding rock-matrix, the solute mobility is considerably getting retarded with increase in fracture properties whereas spreading of solutes is insensitive to properties of fracture-skin.

(iii) Under high fracture-skin porosity, the presence of fracture skin does not significantly influence both the mobility as well as spreading characteristics for both favourable $(n=0.8)$ as well as unfavourable $(n=1.2)$ nonlinear sorption isotherms, from that of linear isotherms.

(iv) The presence of fracture-skin does not significantly affect the mobility and mixing of solutes, when decay is considered.

\section{Acknowledgements}

The authors would like to thank Prof. P P Mujumdar, Indian Institute of Science, Bangalore as well as the anonymous reviewers for their valuable comments and suggestions to improve the quality of the manuscript.

\section{Notation}

The following symbols are used in this paper:

$\mathrm{b}=$ Half fracture aperture, $[\mathrm{L}]$;

$\mathrm{d}=$ Distance from center of fracture to the skin-matrix interface, $[\mathrm{L}]$;

$\mathrm{H}=$ Half fracture spacing, [L];

$\mathrm{C}_{f}=$ Volume concentration of solute in the fracture, $\left[M L^{-3}\right]$;

$\mathrm{C}_{S}=$ Volume concentration of solute in the skin, $\left[M L^{-3}\right]$

$\mathrm{C}_{m}=$ Volume concentration of solute in the matrix, $\left[M L^{-3}\right]$

$\mathrm{C}=$ Volume concentration of solute, $\left[M L^{-3}\right]$;

$\mathrm{C}_{0}=$ Constant concentration for continuous injection of solute source at the inlet of fracture, $\left[M L^{-3}\right]$;

$\mathrm{D}_{L}=$ Hydrodynamic dispersion coefficient in the fracture, $\left[L^{2} T^{-1}\right]$; 
$\mathrm{D}^{*}=$ Free molecular diffusion coefficient of the solute in water, $\left[L^{2} T^{-1}\right]$;

$\mathrm{D}_{S}=$ Effective diffusion coefficient in the fracture-skin, $\left[L^{2} T^{-1}\right]$;

$\mathrm{D}_{m}=$ Effective diffusion coefficient in the rock-matrix, $\left[L^{2} T^{-1}\right]$;

$\mathrm{K}_{d}=$ Proportion or distribution coefficient, $\left[\left(L^{3} M^{-1}\right)^{n}\right]$;

$\mathrm{K}_{f}=$ Surface sorption coefficient of fracture, [L];

$\mathrm{K}_{S}=$ Volume sorption coefficient of the fracture-skin, $\left[L^{3} M^{-1}\right]$;

$\mathrm{K}_{m}=$ Volume sorption coefficient of the rock-matrix, $\left[L^{3} M^{-1}\right]$;

$\mathrm{L}_{f}=$ Length of the fracture along the flow direction, [L];

$\mathrm{M}_{o}=$ Zeroth Temporal moment, [-];

$\mathrm{M}_{1}=$ First Temporal moment, [T];

$\mathrm{M}_{2}=$ Second Temporal moment, $\left[T^{2}\right]$;

$\mathrm{n}=$ Freundlich sorption isotherm exponent, [-];

$\mathrm{R}_{f}=$ Retardation factor of fracture, [-];

$\mathrm{R}_{S}=$ Retardation factor of fracture-skin, [-];

$\mathrm{R}_{m}=$ Retardation factor of rock-matrix, [-];

$\mathrm{S}=$ Sorbed concentration, $\left[M M^{-1}\right]$;

$\lambda=$ Radioactive decay constant, $\left[d a y^{-1}\right]$

$\mathrm{t}=$ Time variable, $[\mathrm{T}]$;

$\mathrm{V}_{0}=$ Mean water velocity in the fracture, $\left[L T^{-1}\right]$;

$\mathrm{V}(\mathrm{x})=$ Velocity of the solute in the fracture corresponding to distance $\mathrm{x},\left[L T^{-1}\right]$;

$T_{1}(\mathrm{x})=$ Normalised first temporal moment at distance $\mathrm{x},[T]$;

$T_{11}(\mathrm{x})=$ Normalised second temporal moment at distance $\mathrm{x},\left[T^{2}\right]$;

$\mathrm{D}(\mathrm{x})=$ Macro-dispersion coefficient in the fracture corresponding to distance $\mathrm{x},\left[L^{2} T^{-1}\right]$;

$\mathrm{x}=$ space coordinate along the flow direction in the fracture plane, $[\mathrm{L}]$;

$\mathrm{y}=$ Space coordinate in the direction normal to the fracture, $[\mathrm{L}]$;

$\bar{x}=$ Mean distance traveled by a solute front along the fracture, [L];

$\alpha_{0}=$ Local fracture dispersivity, [L];

$\rho_{s}=$ Bulk density of the fracture skin, $\left[M L^{-3}\right]$;

$\theta_{s}=$ Fracture-skin porosity, [-];

$\rho_{m}=$ Bulk density of the rock matrix, $\left[M L^{-3}\right]$;

$\theta_{m}=$ Rock-matrix porosity, [-];

$\Delta y(1)=$ Cell width across the fracture-skin interface, $[\mathrm{L}]$

\section{References}

Banton O and Bangoy L M 1997 Hydrogeologie, multiscience ennvironnmentale des eaux souterraines (Hydrogeology, environmental multiscience of groundwater). Presses de l'Universite du Quebec/AUPELF, Sainte-Foy, Quebec, 460 pp

Bardsley W E 2003 Temporal moments of a tracer pulse in a perfectly parallel flow system. Adv. Water Resour. Res. 26(6): 599-607

Driese S G, McKay L D and Penfield C P 2001 Lithologic and pedogenic influences on porosity distribution and groundwater flow in fractured sedimentary saprolite: A new application of environmental sedimentology. J. Sedimen. Res. 71(5): 843-857

Fu L, Milliken K L and Sharp J M 1994 Porosity and permeability variations in the fractured and liesegang-banded Breathitt Sandstone (Middle Pennsylvanian), eastern Kentucky: Diagenetic controls and implications for modelling dual porosity systems. J. Hydrol. 154: 351-381 
Garner T T and Sharp J M 2004 Hydraulic properties of granitic fracture skins and their effects on solute transport. In: Proceedings, 2004 U.S EPA/NGWA, Fractured rock conference: State of the science and Measuring success in remediation, National Groundwater Association, Dublin, Ohio 664-678

Govindarajau R S and Das B S 2007 Moment analysis for sub-surface hydrologic applications. Springer, Dordrecht, The Netherlands

Kreisel I and Sharp J M 1996 Fracture skins in the Brushy Canyon Formation. In: DeMis W D and Cole A G (eds), The Brushy Canyon Play in Outcrop and Subsurface: Concepts and Examples, PBS-SEPM: 96-38, Midland, TX: 147-152

Landrum M T 2000 Hydrogeologic properties of fracture skins and their effects on radionuclide transport: Thesis (Masters). The University of Texas at Austin

Leube P C, Nowak W and Schneider G 2012 Temporal moments revisited: Why there is no better way for physically based model reduction in time. Water Resour. Res. 48: W11527, DOI: 10.1029/2012WR011973

Moench A F 1984 Double-porosity models for a fissured groundwater reservoir with fracture skin. Water Resour. Res. 20: 831-846

Moench A F 1995 Convergent radial dispersion in a double-porosity aquifer with fracture skin: Analytical solution and application to a field experiment in fractured chalk. Water Resour. Res. 31: 1823-1835

Naff R L 1992 Arrival times and temporal moments of breakthrough curves for an imperfectly stratified aquifer. Water Resour. Res. 28: 53-68

Natarajan N and Suresh Kumar G 2010 Radionuclide and colloid co-transport in a coupled fracture-skinmatrix system. Colloids and Surfaces A: Physiochemical and Engineering Aspects 370: 49-57

Phyu T 2002 Transient modeling of contaminant transport in dual porosity media with fracture skins: Thesis (Masters). The University of Texas at Austin

Polak A, Grader A S, Wallach R and Nativ R 2003 Chemical diffusion between a fracture and the surrounding matrix, measurement by computed tomography and modeling. Water Resour. Res. 39(4): 1106

Rasmuson A 1985 Analysis of hydrodynamic dispersion in discrete aquifer networks using the method of moments. Water Resour. Res. 21: 1677-83

Renu V and Suresh Kumar G 2012 Numerical Modeling and Spatial Moment Analysis of Solute Mobility and Spreading in a Coupled Fracture-Skin-Matrix System. Geotechnical and Geological Eng. 30(6): 1289-1302

Robinson N I, Sharp J M and Kriesel I 1998 Contaminant transport in a set of parallel fractures with fracture skin. J. Contam. Hydrol. 31: 83-109

Robinson N I and Sharp J M 1997 Analytical solution for contaminant transport in a finite set of parallel fractures with matrix diffusion. CSIRO Mathematical and Information Sciences Report CMIS-C23: 26

Sekhar M, Suresh Kumar G and Misra D 2006 Numerical modeling and analysis of solute velocity and macrodispersion for linearly and nonlinearly sorbing solutes in a single fracture with matrix diffusion. J. Hydrol. Eng. 11(4): 319-328

Sekhar M and Suresh Kumar G 2006 Modeling transport of linearly sorbing solutes in a single fracture: asymptotic behavior of solute velocity and dispersivity. Geotechnical and Geological Eng., 24: 183-201

Sharp J M 1993 Fractured aquifers/reservoirs; Approaches, problems, and opportunities. In: Hydrogeology of Hard Rocks, Memoires of the 24th Cong. International Assoc. Banks D and Banks S (eds), Hydrogeologists. Oslo, Norway, 24, 615 part 1: 23-38

Sharp J M, Robinson N I, Smyth-Boulton R C and Milliken K L 1995 Fracture skin effects in groundwater transport: In: Mechanics of Jointed and Faulted Rock, Rossmanith H P (ed.), AA Balkeme, Rotterdam: $449-454$

Sharp J M, Kreisel J I, Milliken K L, Mace R E and Robinson N I 1996 Fracture skin properties and effects on solute transport: Geotechnical and environmental implications. Rock Mechanics. Aubertin, Hassani and Mitn (eds), Balkeme, Rotterdam (ISBN 905410838 X)

Sharma P K, Sekhar M, Srivastava R and Ojha C S P 2012 Temporal Moments for Reactive Transport through Fractured Impermeable/Permeable Formations. J. Hydrol. Eng. 17: 1302-1314 
Suresh Kumar G and Sekhar M 2005 Spatial moment analysis for transport of nonreactive solutes in a fracture-matrix system. J. Hydrol. Eng. 10(3): 192-199

Suresh Kumar G and Ghassemi A 2006 Spatial Moment Analysis for Non-Isothermal Quartz Transport and Dissolution/Precipitation in a Fracture-Matrix System. J. Hydrol. Eng. 11(4): 338-346

Suresh Kumar G 2008 Effect of Sorption Intensities on Dispersivity and Macro-dispersion Coefficient in a Single Fracture with Matrix Diffusion. Hydrogeol. J. 16(2): 235-249

Suresh Kumar G 2009 Influence of Sorption Intensity on Solute Mobility in a Fractured Formation. $J$. Environ. Eng. 135(1): 1-7

Valocchi A J 1990 Use of temporal moment analysis to study reactive solute transport in aggregated porous media. Geoderma 46(1-3): 233-247

Weber W J J, McGinley P M and Katz L E 1991 Sorption phenomena in subsurface system concepts, models and effects on contaminant fate and transport. Water Resour. Res. 25(5): 499-528

Woodbury A D and Rubin Y 2000 A full-Bayesian approach to parameter inference from tracer travel-time moments and investigation of scale effects at the Cape-Cod experimental site. Water Resour. Res. 36: $159-171$

Zimmerman M D, Bennett P C, Sharp J M and Choi W J 2002 Experimental determination of sorption in fractured flow systems. J. Contam. Hydrol. 58(12): 51-77 